\title{
Coworking spaces and virtual learning communities in Social Networks: Case Study of \#ElClaustroDeIG on Instagram
}

\section{Raquel Gómez-Martínez}

Universidad de Huelva, España

mail: rgomezmartinez93agmail.com

ORCID: https://orcid.org/0000-0002-3784-0607

\author{
Luis-M. Romero-Rodríguez \\ Universidad Rey Juan Carlos, España \\ ESAI Business School, Universidad Espíritu Santo, Ecuador \\ mail: luis.romeroQurjc.es \\ ORCID: https://orcid.org/0000-0003-3924-1517
}

Este trabajo está avalado por el Proyecto I+D+I (2019-2021), titulado “Youtubers e Instagramers: La competencia mediática en los prosumidores emergentes" con clave RTI2018-093303-B-I00, financiado por Ministerio de Ciencia, Innovación y Universidades de España y el Fondo Europeo de Desarrollo Regional (FEDER) y por el Proyecto I+D-i (2020-2022), titulado "Instagramers y youtubers para el empoderamiento transmedia de la ciudadanía andaluza. La competencia mediática de los instatubers", con clave P18-RT-756, financiado por la Junta de Andalucía, en la convocatoria 2018 (Plan Andaluz de Investigación, Desarrollo e Innovación, 2020) y el Fondo Europeo de Desarrollo Regional (FEDER).

\begin{abstract}
Social networks are consolidated as spaces for the exchange of valuable content. It is not surprising to find spaces for the exchange of good teaching practices in virtual learning communities, so the objective of this study is to analyze, through the case study of \#ElClaustrodeIG on Instagram, the educational content focused on teaching that is shared for the Ibero-American community in Spanish, as well as the analysis of the users who share their experiences and good practices in this social network. The study is exploratory in scope, qualitative-quantitative in design, and correlational-explanatory in nature. Content analysis is first carried out, through an analysis sheet $(\alpha=.695)$ to 300 posts and a self-administered questionnaire, previously validated in construct and content by expert judgment, is applied to 130 users of this hashtag on Instagram in order to analyze their patterns of use, their interests and motivations, their training in ICT and social networks, as well as the impact that the use of this social network has on their professional development and the gratification they expect. The results show that most of the publications are about good practices for primary and preschool education while most of the users think that Instagram is an ideal space for non-formal learning, applying in the classrooms many of the good practices shared in this coworking space.
\end{abstract}

Keywords: collaborative learning, learning communities, informal learning, social media, teacher professional development.

\section{Espacios de coworking y comunidades virtuales en redes sociales: Estudio de caso de \#ElClaustroDeIG en Instagram}

\section{RESUMEN}

Las redes sociales se consolidan como espacios de intercambio de contenidos y experiencias. No es de extrañar que existan espacios de intercambio de buenas prácticas docentes en las comunidades virtuales de aprendizaje, por lo que el objetivo de este estudio es analizar, a través del estudio de caso de \#ElClaustrodeIG en Instagram, los contenidos educativos enfocados a la enseñanza que se comparten para la comunidad iberoamericana en español, así como el análisis de los usuarios que comparten sus experiencias y buenas prácticas en esta red social. Para ello se acude a un estudio de alcance exploratorio, de diseño cuali-cuantitativo y de naturaleza correlacional-explicativo. Primero se realiza un análisis de contenido a través de una hoja de análisis $(\alpha=.695)$ a 300 posts y se aplica un cuestionario autoadministrado, previamente validado en constructo y contenido por juicio de expertos, a 130 usuarios de esta etiqueta en Instagram para analizar sus pautas de uso, sus intereses y motivaciones, su formación en Tecnologías de la Comunicación y la Información (TIC) y redes sociales, así como el impacto que el uso de esta red social tiene en su desarrollo profesional y la gratificación que esperan. Los resultados muestran que la mayoría de las publicaciones tratan sobre buenas prácticas para la educación primaria y preescolar, mientras que la mayoría de los usuarios piensan que Instagram es un espacio ideal para el aprendizaje no formal, aplicando en las aulas muchas de las buenas prácticas compartidas en este espacio de trabajo conjunto.

Palabras clave: aprendizaje colaborativo, comunidades de aprendizaje, aprendizaje informal, redes sociales, desarrollo profesional. 


\section{Introducción}

Recently, a revolution has changed the way of understanding communication, media, and technologies to adapt to citizens' demands. This transformation has been more significant since Web 2.0 and social networks' arrival as tools characterized by interaction, exchange, and content creation (Orta and Chavez, 2010). This way, users assume an active role in collaborative learning that emerges on the Internet (Calle-Álvarez and Ocampo-Zapata, 2019).

This scenario shows that the networks' users have gone from being "consumers» to being "prosumers", in other words, that they create while consuming content. In this way, the influencers and specific influencers of Instagram (Kádeková and Holienčinová, 2018) also arise, which are users who, given the content they share, obtain an organic growth of their accounts, not only in the number of followers but also in interactions -such as likes, comments, and sharing-.

In the educational sphere, the term Technologies for Empowerment and Participation (TEP) emerges, which uses technologies in social environments to give rise to the creation of collective knowledge (Latorre-Iglesias et al., 2018). Modern society offers multiple options to access learning, and one of them is generated by the collaboration and interaction of the members of virtual learning communities, which means that social networks can be understood as an informal learning environment (Barreneche $e t$ al., 2018; Da-Silva and Ferreira, 2016).

This study aims to explore learning communities, coworking spaces, and virtual learning communities for teachers on Instagram to determine the influence it has on the members of these communities, as well as to investigate the claims of the participants, and finally, to define and characterize the different users of this virtual learning community.

\section{Literature review}

\subsection{Media exaptation and new means of interaction}

Socio-cultural and technological transformations occur in parallel, since, following Frost and Postman (1993), new media emerge from social demands, and these, in turn, affect the culture in which we live. This results in what Gould (1991) calls «exaptation», that is, an evolutionary process with a known origin and characteristics that evolve to provide answers to other needs that arise over time.

The current context can be defined as «Information Society» or «Network Society» (Castells, 2001), characterized by the importance of the Internet and Web 2.0 in our consumption habits and information production. These technologies facilitate the creation of social networks, elevating their maximum power through communication and interaction between individuals in current society.

Social networks are understood as self-communication platforms that aim to connect people more effectively and faster (Castells, 2009; Madrigal, 2015). In this way, smartphones and tablets become essential devices for communication and access to information (Flores-Vivar, 2009). As a result, citizens can install multiple applications on their devices to create, share, and access information without spatial-temporal barriers (Morillo, 2001).

Orta and Chávez (2010, p. 2) state that Social networks lead to a high degree of interconnectivity among citizens. In this line arises the concept of «influencer», understood as the ability to guide equals' acts and movements (Arora et al., 2019). Following Elorriaga and Monge (2018), influencers hide behind a digital identity with persuasive potential, significantly affecting their followers (Santamaria-de-la-Piedra and Meana, 2018). Besides, Instagrammers include people who, because of some particular skills, can attract and engage a large number of followers on Instagram (Kádeková and Holienčinová, 2018).

\subsection{Different ways to learn}

Web 2.0 and social networks have meant an alteration in various daily life areas, including, inevitably, how content is learned and consolidated (Pérez-Escoda and García-Ruiz, 2019). Firstly, Pérez and Moliní (2004) and van Merriënboer et al. (2009) distinguish three types of educational situations influenced by the context and conditions in which learning takes place: formal, non-formal, and informal. Formal learning occurs within an educational context (Pereira et al., 2019), and non-formal learning takes place outside curricula linked to formal education (Schugurensky, 2000). On the other hand, informal learning is related to self-learning outside the classroom, being defined by Barreneche et al. (2018) as autonomously developing competencies or arising through digital resources and tools.

The presence of mobile devices leads to the ubiquity of learning, being considered the tool that most promotes non-formal learning (Del-Campo-Cañizares, 2013), as well as life-long learning. These tools enhance the processes of content acquisition by creating learning communities where knowledge is originated and shared (Burgos, 2017). It should be noted that there are different virtual communities, but this research is focused on those learning communities that arise spontaneously in an informal way (Lantz-Andersson et al., 2018) in social networks, blogs, or forums.

As a result, teachers; use social networks (Carpenter et al., 2019) to collaborate with other colleagues working in different schools or institutions (Carpenter and Green, 2017). These virtual communities of like-minded teachers offer the development of collective learning, professional development, the building of personal relationships, emotional support, and ideal coworking space for the exchange of good practices (Shelton and Archambault, 2019). At this point, it is appropriate to relate these online communities to the affinity spaces of Gee (2005) and the communities of practice of Wenger (1998), which are still present in society, although in virtual format (Visser et al., 2014).

This is how the term «teacherpreneurs» arises, who are educators proactively involved in the educational process, sharing their resources, materials, and ideas, in general, through different web platforms (Shelton and Archambault, 2019). This form of informal learning allows educators to collaboratively build knowledge with other colleagues to develop teaching practice (Trust et al., 2016). Therefore, according to Piscitelli et al. (2010), social networks influence education through the collective intelligence formed by groups of prosumers.

This evolution in learning contexts can be linked to the word «knowmad» or «knowledge nomad», coined by Moravec (2013), which, according to Del-Campo-Cañizares (2013), corresponds to individuals who are able to adapt to new circumstances by using creativity and learning possibilities while knowing how to take advantage of technology. According to Shelton and Archambault (2019), teacherpreneurs consider that their experience with the online community of educators has improved their classroom capabilities and inspired them to come up with new ideas and applications for the teaching-learning process. Moreover, if we go into these social networks, we can see that it is increasingly common to find profiles of educators with thousands of followers who are also teachers (Carpenter et al., 2019) since Instagram of- 
fers facilities to create collaborative spaces for educators, reducing geographic time barriers, and even hierarchical and institutional ones (Carpenter et al., 2019).

\section{Materials and methods}

This study will analyze \#ElClaustrodeIG as a Spanish language coworking space for teachers that acts as a virtual learning community. First, the contents of interest will be studied from the users' publications. On the other hand, the influence of this collaborative teaching space on its participants will be investigated.

\subsection{Instruments and procedures}

The present research was developed under a mixed design using qualitative and qualitative approaches-. On the one hand, the publications (posts) were qualitatively analyzed from a grid for content analysis. On the other hand, to know more deeply the objectives, concerns, and motivations of the online community members analyzed, a survey with closed questions, multiple-choice and Likert scales were applied.

\subsection{Sample and participants}

To calculate the sample size, the formula for calculating finite populations is applied. The confidence level is $93 \%$ for publications, while the maximum accepted estimation error is $+/-5 \%$, resulting in 300 publications for content analysis. On the other hand, the 130 users who participated in completing the questionnaire provide a $95 \%$ confidence level and a maximum accepted error of $+/-6 \%$. All research data were collected during June 2020. The 300 publications linked to the hashtag \#ElClaustrodeIG were randomly analyzed, while the 130 users participated voluntarily and anonymously in the completion of the questionnaire. Permission from the university's ethics committee was not required, as the surveys, in addition to being completely anonymous and voluntary, did not collect data that would endanger the identity of the participants (geolocation, IP addresses, etc.).

\subsection{Content analysis}

Content analysis is a technique for interpreting texts in any format (Abela, 2002) that seeks to reveal the central elements of a given event (López-Noguero, 2002). For this purpose, an analysis grid was designed and subsequently validated after an expert judgment was carried out to check the reliability of the research instrument (Robles-Garrote and Rojas, 2015).

To analyze the instrument's internal consistency, we proceeded to calculate the Cronbach $\alpha$ coefficient, which is expressed as a number between 0 and 1 (Tavakol and Dennick, 2011). Internal consistency is generally considered acceptable when its value exceeds .70 (Bland and Altman, 1997; Cervantes, 2005; Terblanche and Boshoff, 2008). To analyze the content analysis grid's internal consistency, JAMOVI statistical software was used, which gave an internal consistency value of .695 , which is very close to the .70 recommended by the researchers. However, other authors, such as Nunnally (1994) and Streiner (2003), state that if the length of the test is too short, as is the case with the seven items relating to the dimensions of the instrument analyzed, the value of alpha is severely reduced, so that the result obtained is considered valid for the reliability of the instrument.

Finally, the analysis grid is composed of different variables divided into four dimensions (Appendix A). To carry out the study, the data from this analysis grid were transferred in .csv to the
Microsoft Excel software and filled in in a dichotomous way with 0 and 1, depending on the presence or absence of the elements studied. It is important to note that the posts' contextualization data, that is, the independent values (date, user, number of followers, etc.), were not filled in in a dichotomous way, but rather numerically or descriptively, as the case may be. Furthermore, in the third dimension, the items' number of likes' and 'number of comments' will also be described with a numerical value (Appendix A).

\subsection{Questionnaire}

With the questionnaires, the respondents' opinions and thoughts are known through different questions (Buendía, 1999). This tool's objective is to know first-hand the objectives, incentives, and stimuli of the participants of Instagram's virtual cloister. The dimensions selected were: personal data, use of Instagram, formation in technologies and social networks, support among members, professional development, and motivation (Appendix B). The variables were coded for convenience, as seen in the questionnaire. Most questions are answered using the Likert scale from 1 to 4 , with 1 being 'strongly disagree' and 4 'strongly agree'. However, there are some more open-ended items for greater depth in the data, such as in the 'Personal Data' or 'Motivation' dimensions, where respondents must choose from the answers offered.

The questionnaire was validated in construct, content, and criteria by the expert judgment method, using 12 researchers of recognized trajectory in education, communication, and Information and Communication Technologies. The criteria for selecting the experts responded to the following indicators: 1) Ph.D. in Education, Pedagogy, Communication or related fields; 2) Research experience of at least ten years and 3) Research in the field of media literacy and education and ICTs. For the calculation of the External Competence Coefficient $[\mathrm{K}=1 / 2(\mathrm{Kc}+\mathrm{Ka})]$, a self-assessment question was also asked about the level of knowledge that the expert claimed to have about the object of research, obtaining an average $(\bar{x})$ of 4.2 on a Lickert scale 1-5. Cohen's Kappa (k) obtained from the instrument's evaluation was $\mathrm{k}=.772$, showing a medium-high level of agreement among the experts.

The Cronbach coefficient $\alpha$ was calculated to obtain the reliability score (Quero, 2010). This procedure was carried out once the respondents had answered the questionnaire, and those items whose answers are quantified with Likert scales were taken into account. Thus, the value of the result of the analysis of Cronbach's coefficient $\alpha$ is .886, which, according to the above, is validated, as it is a value higher than .7 (Tavakol and Dennick, op. cit).

\section{Results}

\subsection{Content analysis}

The first Instagram post with the hashtag \#ElClaustrodeIG was uploaded on September 20, 2017. Of the 300 publications analyzed, most of them have been published this year (2020), specifically 157. In fact, in 2017, there were few publications linked to the hashtag analyzed, as only one publication from that year has been found. Finally, with intermediate data, we find 2018 and 2019 , the latter being the year in which publications are doubled.

As for the users who publish content using the hashtag analyzed, it can be noted that the 300 randomly selected publications correspond to a total of 117 different users, which seems to indicate that this is a community where users publish content frequently and not in isolation, with an average of 2.37 publica- 
tions per user. Of the 300 publications, 229 are good practices for Elementary School, 120 for Early Childhood Education, and only 19 for High School. Of the 117 users analyzed, 90 are Elementary School teachers, followed by 44 in Kindergarten and 10 in Secondary School, while 27 of them can teach in both Kindergarten and Primary School. The sum of all the different users' followers is 775,589, with 205,000 followers being the most popular user and 67 the lowest number of followers.

\section{Dimension 1: Content of publications}

The most significant content, with 209 publications, corresponds to publications that include presentations, explanations, or examples of classroom resources. Secondly, publications related to the experience, both personal and professional, of users. The third most frequent content of the posts corresponds to examples and/or explanations of different activities to be carried out in the classroom. As for the areas related to publications, the 'Foreign Languages' category, which includes English, French and Spanish - when taught as a second language - is the most represented with 71 entries. Then there are the publications of 'Mathematics' (39), followed by 'Language' (21). Analyzing the content according to practices and methodologies, the most frequent publications are those referring to 'websites' (38), followed by 'emotional education' (21) and the use of 'educational apps' (20), followed by the 'Gamification' (16) and 'Collaborative or Cooperative Learning' methodologies (13). The least represented are related to 'evaluation' (10), 'Project Based Learning (PBL)' (9), 'Content Creation Programs' (6), 'Augmented Reality' (3), and 'Flipped Classroom' (1).

\section{Dimension 2: Formats}

After analyzing the content, the second dimension studied aims at exploring the format of the publications (posts). Thus, almost all publications (287) contain images. Similarly, the description is one of the characteristics shared by most publications (265). It should be noted that the 300 analyzed posts contain characters in the description, however, were discarded those that did not provide information or explanation about the image or video they were attached to, since some descriptions only include hashtags or not very relevant information, including the real description within the images or videos. To finish with this dimension, the presence of 29 publications with audiovisual content stands out, 24 of them in video format, and 5 in IGTV (videos in portrait format up to 10 minutes or up to 60 minutes for verified and popular accounts).

\section{Dimension 3: Interaction}

The third dimension studies the different interactions that originate from publications. Of the 300 publications, the post that obtained the most "likes" had 2,701, while the average $(\bar{x})$ of comments per publication was 209. Furthermore, it should be pointed out that, of the 300 publications analyzed, 244 have comments, adding up to a total of 5558 in the hashtag \#ElClaustrodeIG, having 861 comments the publication with the highest number of interactions.

Besides, the content of the comments was also analyzed. Of the 244 publications with comments, 216 of them received written support, such as "I love it!" or "I'm writing it down". On the other hand, in 204 publications, the users expressed their opinions that serve to feed the experiences and/or activities proposed. One hundred seventy-three (173) publications contain comments that show agreement and assertiveness among users that act as a form of approval among teachers. Likewise, 109 publications received comments of gratitude, 86 contain personal experiences, and 81 collect doubts that other «edugrammers» raise. With the less sig- nificant values, five publications were examined with comments that showed disagreement with the above, and 29 publications proposed suggestions with the intention that the rest of the users take them into account.

\section{Dimension 4: Other connections}

The fourth dimension studies the different connections between the publications studied. Thus, 300 publications use hashtags to link publications with more topics. Thus, despite having analyzed the publications with the hashtag \#ElClaustrodeIG, all publications contain a great diversity of hashtags, such as \#Claustrodeinstagram, \#claustrodeig, \#educacion, \#claustrovirtual, \#aprendizaje, \#recursos o \#educacionprimaria. In addition, 70 of the 300 publications studied have connections to other accounts, both in hashtags (\#) and mentions (@).

\subsection{Questionnaire}

The questionnaire was active from May 15 to June 15, 2020, on the Google Forms platform. During the activity period, 130 responses were recorded. Of the 130 respondents, $86 \%$ identified themselves as female, $13 \%$ as male, and $1 \%$ as neither. It is also found that $98.5 \%$ work in Spain, with only two respondents working in other countries; $0.8 \%$ (1) in Chile and $0.8 \%$ (1) in Mexico. The fourth and fifth questions are related to the stage and specialty of the 130 teachers surveyed. $69 \%$ are Elementary Education teachers; $19 \%$ are Preschool teachers; $12 \%$ are High School teachers, and $0.8 \%$ (1) are University professors.

In terms of specialties, foreign languages are the most represented by $30 \%$. In the second place, with $29 \%$, are Elementary Education teachers without any specific specialty. Thirdly, 17\% represent Therapeutic Pedagogy specialists. Less represented are teachers of Hearing and Language (4\%), Physical Education (4\%), Mathematics (3\%), Social and/or Natural Sciences (2\%), and Music (2\%). Concerning the type of schools in which the participants work, $65 \%$ work in public centers, $25 \%$ in subsidized institutions, and $10 \%$ in private schools. Regarding the respondents' teaching experience, $37 \%$ have been working for 1 to 4 years, and $32 \%$ have 5 to 10 years. $12 \%$ represent the groups of less than one year and more than 15 years, that is, the newest and the most veteran. Finally, the group with the least representation includes teachers with between 11 and 15 years of teaching experience (9\%).

\section{Dimension 1: Use of Instagram}

In Table 1, nine of the ten items relating to the first dimension have been included. The remaining item (CD1B) was not answered using the Likert scale, but with affirmation or negation; therefore, it will be analyzed separately later.

The CD1A question aims to find out how many users use this social network professionally. The mean $(\bar{x})$ of the answers corresponds to 3.15, that is, a value between 'Agree' and 'Strongly-agree', with the mode $(\mathrm{Mo}(\mathrm{X}))$ set at 4 , the maximum score. However, an analysis of the standard deviation $(\mathrm{s}(\sigma))$ of this item shows some dispersion of the data concerning the average value. In this way, 100 people agree to it, compared to 30 who do not. Among all the answers, 55\% of the respondents say they 'strongly-agree'. About the second item-CD1B-, 77\% of the participating users state that they share publications with educational content on this social network. As previously stated, this question was answered dichotomously (yes/no).

The variable CD1C measures the time spent on the Instagram activity. $64 \%$ revealed that they spend a considerable amount of time using this social network. If we look at Table 1, we can see that it is one of the three variables whose average $(\bar{x})$ has a value 
Table 1.

Use of Instagram

\begin{tabular}{|c|l|l|l|l|l|l|l|l|l|}
\cline { 2 - 9 } \multicolumn{1}{c|}{} & CD1A & CD1C & CD1D & CD1E & CD1F & CD1G & CD1H & CD1I & CD1J \\
\hline Sample & 130 & 130 & 130 & 130 & 130 & 130 & 130 & 130 & 130 \\
\hline Mean $(\bar{x})(1-4)$ & 3.15 & 2.76 & 2.49 & 3.52 & 2.41 & 3.42 & 3.05 & 3.18 \\
\hline Mode $(\mathrm{Mo}(\mathrm{X}))(1-4)$ & 4 & 3 & $1-4$ & 4 & 1 & 4 & 3 & 4 & 4 \\
\hline $\mathrm{S}(\sigma)$ & 1.12 & 0.95 & 1.14 & 0.79 & 1.28 & 0.83 & 0.79 & 0.85 & 0.88 \\
\hline
\end{tabular}

below 3. However, the mode $(\operatorname{Mo}(X))$ is in 3, that is, 'agree' with the statement "I spend a lot of time on Instagram to share or get educational content" (CD1C). Consequently, when looking at all the data, it can be seen that most of the users surveyed spend quite a lot of time on this social network. Also, the value of the standard deviation (s $(\sigma)$ ) establishes a low degree of data dispersion as a function of the mean $(\bar{x})$.

For CD1D, the frequency with which users post content on Instagram using the \#ElClaustrodeIG hashtag is analyzed. The average $(\bar{x})$ is around 2.5, between the values 'Disagree' and 'Agree'. It is also the only item with two different fashion values $(\mathrm{Mo}(X))$, these being 1 and 4, the lowest and highest possible score. What is clear is that the responses of the 130 users are very varied and that, therefore, each one makes Instagram publications as often as they feel appropriate. Therefore, the standard deviation $(\mathrm{s}(\sigma))$ shows a value above 1 .

The variable CD1E examines the support towards users and the publications that are shared in the virtual community. Table 1 shows that the average $(\bar{x})$ of the responses is over 3.5 , between 'Agree' and 'Strongly agree'. Besides, the most common response $(\mathrm{Mo}(\mathrm{X}))$, represented by $66 \%$, was the maximum value -Strongly agree-. On the other hand, the standard deviation $(\mathrm{s}(\sigma))$ has a low value (0.76), so there is no relevant data dispersion.

The item CD1F studies other social networks or websites for a wider distribution of the contents shared on Instagram. The mean $(\bar{x})$ of the responses was 2.4, and, in the same line, mode $(\mathrm{Mo}(\mathrm{X}))$ indicates that the most recorded response, specifically on 48 occasions, was 'Strongly disagree'. Its standard deviation $(\mathrm{s}(\sigma))$ contains the highest value, which means a high degree of data dispersion.

Based on users' responses to item CD1G, most users (88\%) believe that sharing content on Instagram is a significant time investment, while $75 \%$ believe it is worth the time investment, corresponding to item CD1H. In both questions, the mean $(\bar{x})$ is above 3 [strongly agree], and the mode $(\operatorname{Mo}(X))$ is 3 and 4, respectively, so these are positive values. Furthermore, the standard deviation $(\mathrm{s}(\sigma))$ of this item does not provide significant dispersion.

The answers of the variable CD1I show that $75 \%$ of the users consider Instagram an appropriate platform for sharing the different educational contents, and they believe that it should have a more significant presence in the educational field. On the other hand, taking into account the opinions of the item CD1J, 81\% of the respondents claim to continue using this social network for educational purposes in the future. The modes $(\mathrm{Mo}(\mathrm{X}))$ of these last two items coincide with the highest value, and the mean $(\bar{x})$ corresponds to a value greater than 3 [agree / strongly agree].

From another angle, Bartlett's Sphericity Test is carried out to evaluate the applicability of factorial analysis (EFA). This test related to the present dimension variables determines that it is a significant model since it provides a value lower than 0.05 (Ferrando and Anguiano-Carrasco, 2010). The KMO sampling adequacy measure seeks to clarify whether the variables can be adequately factored in by relating the correlation coefficients between them. The total value of the KMO suitability measure is 0.875 , so it is a remarkable relationship. Therefore the factorial model is significant.

As shown in Figure 1, containing the value of the Pearson correlation coefficient of the items in the first dimension, there is a valid correlation between the variables since all the values are $\geq 0$. However, there is a wide range of values representing different types of correlation, the strongest being those between the items CD1I and CD1J (0.619), CD1A and CD1C (0.645), and between CD1A and CD1J (0.672). On the other hand, the least significant correlations are those between CD1E and CD1F (0.0743), CD1F and CD1H (0.0955), CDFG, and CD1G (0.0768), CD1F, CD1J and CD1F (0.0835), and CD1I (0.0256).

Figure 1 shows that the frequency histogram of item CD1A shows a rightward orientation, establishing that users tend to use Instagram for education-related purposes. Another histogram with a proper inclination towards the right corresponds to the variable CD1E, which confirms that there is a predisposition of the users to support the contents published by the rest of the users. Similarly, and confirming the answers, the Histogram for item CD1G states that users consider the use of Instagram to be a considerable time investment. Likewise, the diagram representing the trends of the CD1I establishes that Instagram is a social network

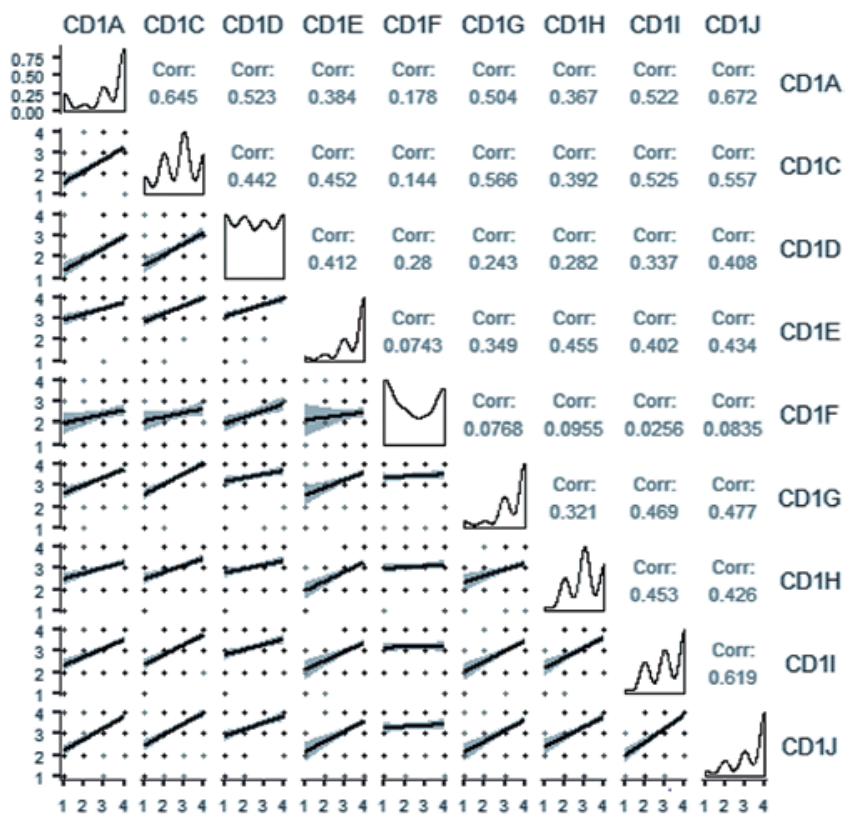

Figure 1. Pearson's correlation histogram of dimension 1 (use of Instagram). 
that fits the characteristics of informal learning and should have a more significant presence in the educational field. In the same direction, the Histogram of the variable CD1J shows an agreement among users regarding the continuity of this social network's use for educational purposes.

In contrast, the frequency histogram of item CD1F is bimodal; that is, it exhibits two peaks of similar frequency that, moreover, turn out to be the opposite. Therefore, what the Histogram of this variable represents is that there are two types of users: those who do use other media to obtain greater dissemination and those who do not, with the relatively more significant being users who use other media to maximize the visibility of the educational approach or good practice.

\section{Dimension 2: Training on ICT and social networks}

Variable CD2A corresponds to the ICT training that users may have received. $52 \%$ of respondents said they had received this training, which contrasts with the answers to the following question, the CD2B, where 95\% manifest themselves as autodidacts in ICT. As shown in Table 2, the mean $(\bar{x})$ of the responses indicates a value close to 4 [strongly agree], being this value the most frequent response $(\mathrm{Mo}(\mathrm{X}))$. Despite declaring that they have received training in Information and Communication Technologies (ICT), most of the users who have participated in the survey consider that this training has been scarce or insufficient, as they have had to learn by themselves finally.

Table 2.

Training on ICT and social networks

\begin{tabular}{|c|l|l|l|}
\cline { 2 - 4 } \multicolumn{1}{c|}{} & CD2B & CD2D & CD2E \\
\hline Sample & 130 & 130 & 130 \\
\hline Mean $(\overline{\mathbf{x}})(\mathbf{1 - 4})$ & 3.62 & 3.68 & 3.51 \\
\hline Mode $(\mathbf{M o}(\mathbf{X}))(\mathbf{1 - 4})$ & 4 & 4 & 4 \\
\hline $\mathbf{s}(\boldsymbol{\sigma})$ & 0.60 & 0.63 & 0.65 \\
\hline
\end{tabular}

Concerning specific training in social networks, which is reflected in the responses to item CD2C, 85\% said they had not received it, which, this time, is in line with the responses to the question CD2D, where $94 \%$ claim to be self-taught in these matters. As shown in Table 2, the answers' mean $(\bar{x})$ is 3.68 , very close to 4 [strongly agree]. The variable CD2E studies the interest in training in the educational and informative use of social networks, about which $93 \%$ of the respondents answered 'agree' (3), and most of them expressed 'Strongly agree' (4). In line with the other values, the standard deviation $(\mathrm{s}(\sigma))$ of the indicators linked to the second dimension corresponds to a low value of data dispersion.

Bartlett's Sphericity Test states that it is a significant model for performing exploratory factor analysis (EFA) since the result is less than 0.005 . However, the $\mathrm{KMO}$ test provides a total value of 0.499 , which corresponds to a low ratio between the variables. On the other hand, considering the data for analyzing Pearson's correlation coefficient explained ut supra, a relevant correlation is perceived between CD2B and CD2D items (0.712), while the other values show a negative correlation.

As shown in Figure 2, the frequency histogram of the variable CD2B - very similar to the CD2D Histogram - reflects the participants' tendency towards autodidactic training in ICT and social networks. As for the Histogram of the variable CD2E, it is easily detectable a trend to the right that confirms the interest in training in the subjects previously mentioned.

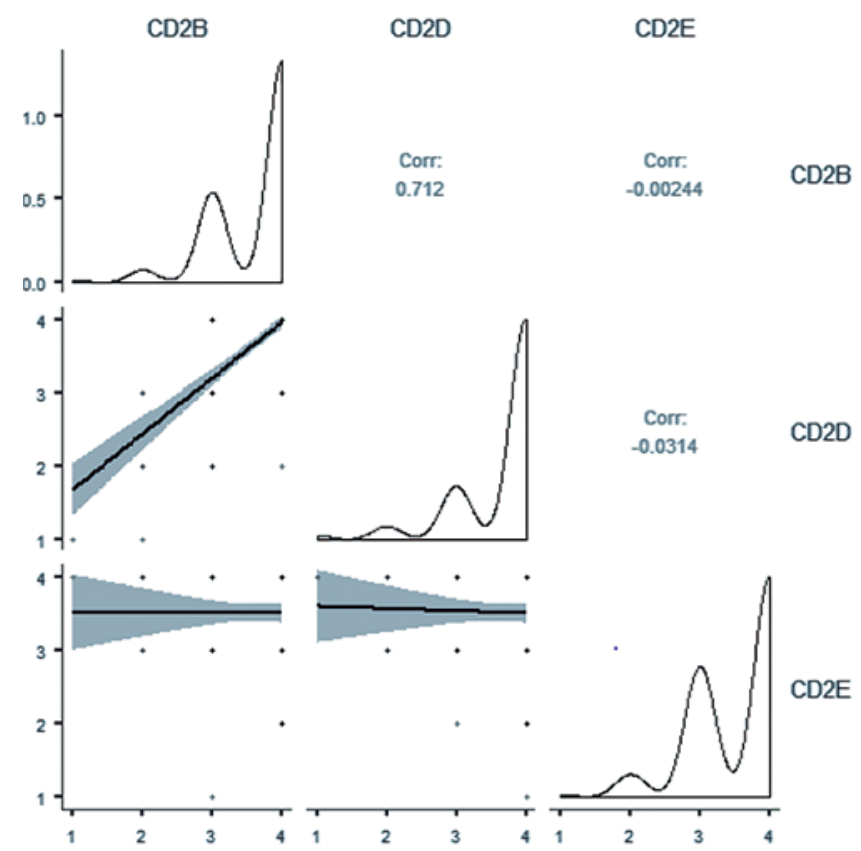

Figure 2. Pearson's correlation histogram of dimension 2 (Training on ICT and social networks)

\section{Dimension 3: Support}

To the variable CD3A, $82 \%$ of the respondents answered with options 3 and 4 , giving an average $(\bar{x})$ of 3.26 and being the mode $(\mathrm{Mo}(\mathrm{X}))$ the maximum value that expresses the maximum degree of agreement (4). Thus, it can be deduced that the majority of users feel identified with the community studied. However, the value of the standard deviation $(\mathrm{s}(\sigma))$ is relatively high $(0.92)$, which indicates that there is dispersion in the data offered to the value of the mean.

Table 3.

Support

\begin{tabular}{|c|c|c|c|c|}
\hline & CD3A & CD3B & $\mathrm{CD} 3 \mathrm{C}$ & CD3D \\
\hline Sample & 130 & 130 & 130 & 130 \\
\hline Mean $(\bar{x})(1-4)$ & 3.26 & 3.16 & 3.18 & 2.33 \\
\hline Mode $(\operatorname{Mo}(X))(1-4)$ & 4 & 4 & 4 & 1 \\
\hline $\mathrm{s}(\sigma)$ & 0.92 & 0.93 & 0.93 & 1.07 \\
\hline
\end{tabular}

The CD3B variable explores whether support and appreciation of work, even if virtual, manifest by greater involvement of active users. To the statement "I belong to a community where my work is valued and respected, and that encourages me to continue sharing content", $77 \%$ of respondents agreed. The values obtained in the following item [CD3C] are very similar, although including the feeling of support explicitly. In addition, the values offered by the standard deviation $(\mathrm{s}(\sigma))$ in both items are identical $(0.93)$ and relatively significant.

For the CD3D variable, $45 \%$ say they feel more understood in the virtual cloister than in face-to-face spaces, compared to $55 \%$ who say the opposite. Also, the average $(\bar{x})$ for this item is 2.3, 
which corresponds to 'Disagree', and the mode $(\mathrm{Mo}(\mathrm{X}))$ has been 1 , which expresses the highest possible degree of disagreement. However, despite the percentage of users who deny feeling more supported in the virtual cloister, there is also a significant representation of people who claim the opposite, as can be deduced, besides, from the data offered by the standard deviation $(\mathrm{s}(\sigma))$ of the item CD3D with a 1.07, being the highest value of data dispersion.

The result of Bartlett's Sphericity Test shows that it is a significant model for performing exploratory factor analysis (EFA), as it provides a value of less than 0.005. As for the KMO test, the total value indicates a low ratio between the variables since the result is 0.682 , although independent variables have a higher ratio value, such as CD3A (0.807) and CD3D (0.703). Pearson's correlation coefficient shows a significant relationship between CD3B and CD3C (0.762) and the rest of the values. However, even though they are sufficient correlations, none of them reveal any other remarkable relationship since they correspond to moderate relations between the variables.

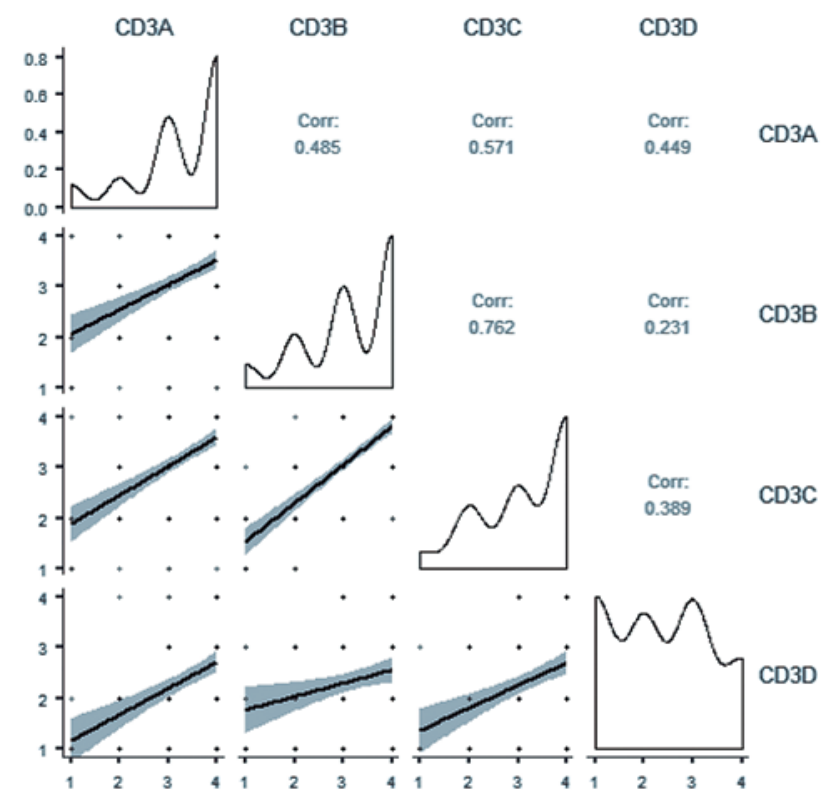

Figure 3. Pearson's correlation histogram of dimension 3 (support)

The rightward trend of the frequency histogram of the CD3A variable means that the users surveyed feel part of a community with which they share philosophy and interests. Thus, the Histogram of the CD3B item reflects the trend that indicates that most participants have a feeling of respect and mutual support that invites them to continue participating and contributing to this collective. Similarly, the trend to the right of the CD3C frequency Histogram shows that feeling the support of other users encourages them to develop their skills as teachers, embracing both participation in the virtual learning community and the transmission or implementation of what they have learned on Instagram in the classroom.

\section{Dimension 4: Professional development}

This dimension analyses the professional development through Instagram of the respondents. The means $(\bar{x})$ of the responses to the first three items have a value greater than 3 , which means that the respondents "agree" with the statement to implement resources, methodologies, or activities proposed by other colleagues (CD4A), that they have improved their practice as teachers thanks to the content shared by the other users (CD4B) and that they learn from the different contributions (CD4C).

Table 4.

Professional development

\begin{tabular}{|c|c|c|c|c|}
\hline & CD4A & $\mathrm{CD} 4 \mathrm{~B}$ & $\mathrm{CD} 4 \mathrm{C}$ & $\mathrm{CD} 4 \mathrm{D}$ \\
\hline Sample & 130 & 130 & 130 & 130 \\
\hline Mean $(\bar{x})(1-4)$ & 3.45 & 3.04 & 3.42 & 1.58 \\
\hline Mode $(\operatorname{Mo}(X))(1-4)$ & 4 & 4 & 4 & 1 \\
\hline $\mathrm{s}(\sigma)$ & 0.74 & 0.96 & 0.78 & 0.98 \\
\hline
\end{tabular}

The most usual answer $(\operatorname{Mo}(X))$ to the three above questions is that of maximum conformity [strongly agree]. Analysis of the data for standard deviation $(\mathrm{s}(\sigma))$ shows that items CD4B and CD4D (0.96 and 0.98, respectively) have higher dispersion values than the values of variables CD4A (0.74) and CD4C (0.78). However, the CD4D variable shows that the interactions in Instagram do not tend to go beyond the screens, as the average $(\bar{x})$ of the responses hardly exceeds 1.5 and the mode $(\mathrm{Mo}(\mathrm{X}))$ corresponds to 1 [strongly disagree], making it clear that there are not too many face-to-face meetings between users. However, 23 respondents, representing $18 \%$ of the sample, claim to have participated in presential meetings.

Bartlett's Sphericity test also determines that it is a significant factorial analysis model, as its result is less than 0.005 . However, the KMO test sets a low ratio between the variables (0.697). It should be noted that this is a value close to 0.7 , which is already considered to be a moderately relevant correlation. Despite this, there are dependent variables with more significant values, such as CD4A (0.723), CD4C (0.700), and CD4D (0.810).

Pearson's correlation coefficient of the fourth dimension items gives values corresponding to effective relationships, although with shallow figures. Thus, the most significant correlation is be-

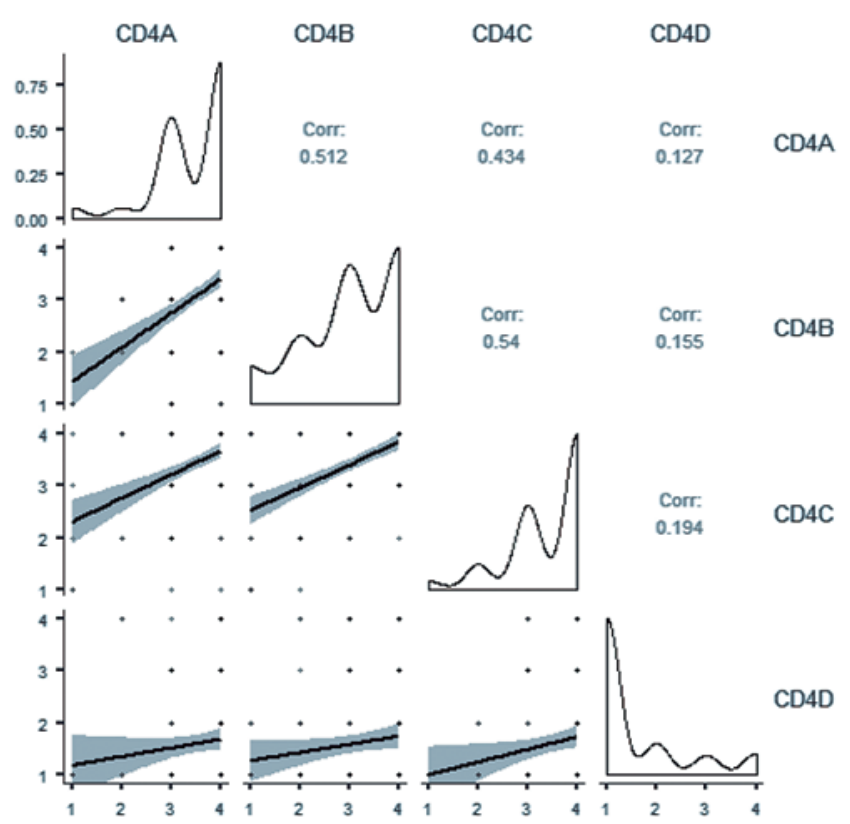

Figure 4. Pearson's correlation histogram of dimension 4 (Professional development) 
tween variables CD4A and CD4B (0.512) and CD4B and between CD4C (0.54), while the rest of the correlations are weak.

The data reflected in the frequency histogram of item CD4A show that there is an inclination to put into practice what has been learned in the virtual cloister, and there is an agreement as to the modification and improvement of teaching practice from being part of \#ElClaustrodeIG. This also coincides with the trend to the right of the CD4B Histogram, understanding that it is a space of co-learning among the online community members, according to the Histogram of the CD4C variable. On the other hand, the Histogram of the CD4D variable shows a leftward tilt, which means that, so far, it is a virtual community, that is, its members do not usually participate in in-person meetings with other users.

\section{Dimension 5: Motivation and interests}

The CD5A variable, unique in this dimension, explores whether users seek to obtain gratifications of some kind in exchange for the content they publish on this social network. The responses show that the average user is looking for a rating for their contribution to the educational community. The value of the standard deviation $(\mathrm{s}(\sigma))$, on the other hand, is close to 1 , which denotes a certain degree of dispersion in the responses. Furthermore, it is interesting to add that 79\% 'agree' (3) with the statement to expect some kind of assessment from other users, with 50\% saying they 'strongly agree' (4). On the contrary, 21\% declared against seeking recognition for their participation.

Table 5 .

Motivation and interests

\begin{tabular}{|l|l|l|l|l|}
\cline { 2 - 5 } \multicolumn{1}{c|}{} & Sample & Mean $(\overline{\mathrm{x}})(\mathbf{1}-4)$ & Mode $(\operatorname{Mo}(\mathrm{X}))(1-4)$ & $\mathrm{s}(\sigma)$ \\
\hline CD5A & 130 & 3.21 & 4 & 0.96 \\
\hline
\end{tabular}

The CD5B variable was designed to establish the content of the most significant interest to users participating in the \#ElClaustrodeIG. To this end, nine categories were proposed, from which respondents chose three options. According to the results obtained, teachers in this virtual cloister are mostly interested in resources (121) and innovative methodologies (105), followed by classroom activities (59), personal experiences (35), and evaluation strategies and techniques (27). With less preference were selected the categories that include contents related to the competitions -examinations of accreditation to teaching in Spain- (16) and scientific content (10). Finally, item CD5C determines the reason for the teachers' participation in the \#ElClaustrodeIG. As with the previous question, different reasons were given for participants to choose two of them. Thus, it is clear that the most common reasons are training (75) and innovation (75), followed by altruistic reasons (32) and then recognition (13).

\section{Discussion}

This work has reaffirmed the thesis of Ordóñez (2003), which states that science and technology depend on certain social contexts and specific needs. Furthermore, according to Pérez-Escoda and Garcia-Ruiz (2019), one of the significant contributions of social networks has been the transformation in terms of learning, as expressed throughout this research.

According to Madrigal (2015), the goal of social networks, and therefore of Instagram, is the connection between people to facilitate communication. In the same vein, Elogia (2019) show that the social network that is most evolving in Spain is Instagram. Prob- ably, taking into account the contributions of Gutiérrez-Cortés et al. (2019), the progress of this social network maybe since it is the means that best suits the needs of individuals in current society, confirming, in the same way, the idea of Carpenter et al. (2019) that the use of social networks is increasingly common and, in this specific case, of Instagram among teachers to collaborate and share content and experiences with colleagues located in different geographical locations (Carpenter and Green, 2018; Shelton and Archambault, 2019).

In \#ElClaustrodeIG the activity of at least 250 people has been evidenced, and, on the other hand, the existence of other hashtags is known, to which more publications with educational content are linked. In this context, virtual communities and movements are created (Canaza-Choque, 2018), where collective intelligence (Levy \& Bonono, 1997) plays an essential role (O'Reilly, 2005). With the cooperation of different participants, multiple fields of knowledge can be covered that would be more difficult to access individually.

Instagram's virtual cloister promotes social learning by exchanging knowledge and strengthening interpersonal relationships (Jenkins, 2009). On the other hand, according to Romani and Kuklinski (2007), one of the four pillars of Web 2.0 is social networks, and it has been possible to corroborate that the active participation of its users as a characteristic of \#ElClaustrodeIG is irrefutable (Orta and Chávez, 2010). Furthermore, the users are the protagonists of the networks since the collaboration, according to Calle-Álvarez and Ocampos-Zapata (2019), leads to new learning. The above is what Jenkins and Ito (2015) describe as «participatory culture», also present in this case study.

Learning generated in informal learning contexts tends to be more meaningful and lasting (Jenkins, 2009). Therefore, in addition to confirming the occurrence of learning from the use of Instagram, users guarantee that they will continue to use this social network as a means of learning in the future. Thanks to social networks such as Instagram, «ubiquitous learning» can be mentioned (Cabero, 2015). Similarly, it is significant to highlight that, according to Jenkins (2009) and after having analyzed the surveys made to several users of \#ElClaustrodeIG, the culture of convergence does not differ between producers and consumers. However, users are prosumers since they share content and thoughts, as well as learning and, at the same time, being the object of learning and helping the community (Jordán-Correa et al., 2017).

It can also be indicated that some users of this virtual cloister are Influencers (Elorriaga and Monge, 2018), as they have a digital identity and have a substantial impact on their followers (Rego-Rey and Romero-Rodríguez, 2016), as well as creating emotional links between them, based on supportive comments or agreements. Therefore, the thesis of Vizcaíno-Verdú et al. (2019) is affirmed, which states that Instagram is a media that influences identities and social behavior, since, as has been stated in this study, the existence of influential teachers with thousands of followers is confirmed (Carpenter et al. 2019). This virtual faculty also uses Empowerment and Participation Technologies to create and share knowledge through Instagram. Also, users of \#ElClaustrodeIG benefit from technology to influence and create trends (Montero, 2014), considering this social network a tool for citizen participation where knowledge is built collectively (Latorre-Iglesias et al., 2018).

\#ElClaustrodeIG is an environment outside geographical and time barriers (Carpenter et al., 2019) where the support that exists between the different members leads to both personal and professional satisfaction (DeAngelis et al., 2013), space where reflection on educational practice is facilitated (Dewert et al., 2003; Vescio et al., 2008) based on the offer of comments, advice and personal 
experiences (Stegman, 2007) - as evidenced by the results - and where professional learning and emotional support is developed (Shelton and Archambault, 2019) among the participating teachers.

Moreover, this is a fundamentally virtual phenomenon since, as the study results reflect, most of them have not extrapolated this collaboration to the presential format. Hence, the online route works more successfully for the virtual faculty, coinciding with Gulamhussein's hypotheses (2013). Finally, this research shows that the vast majority of respondents consider that they have improved their teaching practice based on content shared by other users (Shelton and Archambault, 2019) and, therefore, that social networks, and specifically Instagram, have a particularly significant - and continuously growing - role within the educational environment (Pérez-Escoda and García-Ruiz, 2019).

\section{Conclusions}

The users of \#ElClaustrodeIG are teachers working in Spain, with ages ranging from 18 to 34 years and with teaching experience between 1 and 10 years. Also, there is a higher representation of Primary Education teachers, specifically teachers linked to foreign languages, working mostly in public schools. On the other hand, according to the numbers of 'likes' and followers that have been studied, it is intuitive that, beyond the active users, those who create and share content, there are also many passive participants behind the hashtag \#ElClaustrodeIG. The average number of followers of profiles examined is 6629 , and the highest number of followers found is 205,000 , classifying the users of this virtual cloister in the category of influencers Instagrammers.

The general trend in the publications' content is that they try to provide examples of educational resources and classroom activities, as well as narrating personal experiences of the users generally linked to the professional field - and mainly related to language classes.

About practices and methodologies, it is quite frequent to come across publications that refer to websites. One of the reasons for the existence of these virtual communities is the support among its members, which can be evidenced by the 'likes', the comments, and also by the creation of links and interpersonal relationships that have been created and that are reflected from labels, mentions, and collaborations among different users.

In short, the \#ElClaustrodeIG could be defined as a collaborative environment between edugrammers -teachers who use Instagram to share educational content- that acts as a repository of different educational practices, methodologies, or resources and that leads to the professional development of teachers. The community is characterized by an unquestionable interaction between its members that includes reflections, collaborations between different accounts to create materials, or comments that lead to learning.

Also, it is possible to define users based on a classification of edugrammers. Prosumer edugrammers use Instagram to share education-related content with the rest of the online community; consumer edugrammers follow edugrammers to learn and implement resources and materials but do not publish educational content. Finally, edugrammers influencers have a significant network of followers and, therefore, positively influence the virtual educational community.

However, the continually changing nature of all the study elements must be taken into account. Similarly, one is aware of the existence of a great multitude of hashtags. Therefore, it would be interesting to study the content of other hashtags for further comparison as future research. From another point of view and linked to the universe of social networks, a study of teachers' reputation based on their presence in networks could be useful.

\section{References}

Abela, J. A. (2002). Las técnicas de análisis de contenido: una revisión actualizada. Fundación Centro Estudios Andaluces,10(2), 1-34. https://bit.ly/3ghXZL7

Arora, A., Bansal, S., Kandpal, C., Aswani, R., \& Dwivedi, Y. (2019). Measuring social media influencer index: Insights from Facebook, Twitter and Instagram. Journal of Retailing and Consumer Services, 49, 86-101. https://doi.org/10.1016/j. jretconser.2019.03.012

Barreneche, C., Polo Roja, N. D., \& Menéndez-Echavarría, A. L. (2018). Transmedia Literacy in Colombia: Informal learning strategies of young gamers in precarious contexts. Chasqui. Revista Latinoamericana de Comunicación, 137, 169-187. https:// doi.org/10.16921/chasqui.v0i137.3510

Bland, J. M., \& Altman, D. G. (1997). Statistics notes: Cronbach's alpha. BMJ, 314(7080), 572. https://doi.org/10.1136/ bmj.314.7080.572

Buendía, L. (1999). Modelos de análisis de la investigación educativa [Models of analysis of educational research]. Alfar. https:// bit.ly/31wtSLX

Burgos, E. (2017). Informal learning and transmedia skills. Temas de Comunicación, 34-35, 26-41. https://bit.ly/2VCOGgX

Cabero, J. (2015). Reflexiones educativas sobre las tecnologías de la información y la comunicación (TIC). Tecnología, Ciencia y Educación, 1, 19-27. https://bit.ly/31zNKOb

Calle-Álvarez, G., \& Ocampo-Zapata, D. (2019). Some possibilities of integrating web 2.0 into education. RHS: Revista Humanismo y Sociedad, 7(1), 69-84. https://doi.org/10.22209/rhs.v7n1a05

Canaza-Choque, F. A. (2018). The society 2.0 and the mirage of social networks in liquid modernity. Crescendo, 9(2), 221-247. https://bit.ly/2BZPntW

Carpenter, J., Morrison, S., Craft, M., \& Lee, M. (2019). Exploring how and why educators use Instagram. Proceeding of Society for Information Technology \& Teacher Education Annual Conference [Conferencia]. Association for the Advancement of Computing in Education (AACE), Las Vegas, NV, United States. https://bit.ly/2NNTgEQ

Carpenter, J., \& Green, T. (2018). Self-directed professional learning and educator self-efficacy: The case of Voxer. Self-Efficacy in Instructional Technology Contexts, 163-181. https://doi. org/10.1007/978-3-319-99858-9_10

Castells, M. (2001). The Information Age: Economy, Society and Culture. Siglo veintiuno editores. https://bit.ly/3geXIsn

Castells, M. (2009). Communication Power. Alianza Editorial. https://bit.ly/3dNuGOR

Cervantes, V. (2005). Interpretaciones del coeficiente alpha de Cronbach. Avances en medición, 3(1), 9-28. https://bit. ly/3dLEh8N

DeAngelis, K. J.,Wall, A. F., \& Che, J. (2013). The impact of preservice preparation and early career support on novice teachers' career intentions and decisions. Journal of Teacher Education, 64(4), 338-355. https://doi.org/10.1177/0022487113488945

Del-Campo-Cañizares, E. (2014). M-learning and Informal Learning in Higher Education through mobile devices. Historia $y$ Comunicación Social, 18, 231-242. https://doi.org/10.5209/ rev_HICS.2013.v18.44239

DeWert, M. H., Babinski, L. M., \& Jones, B. D. (2003). Safe passages providing online support to beginning teachers. Journal of Teacher Education, 54(4), 311-320. https://doi. org/10.1177/0022487103255008 
Elogia (Ed.) (2019). Estudio anual de redes sociales 2019 [Annual study of social networks 2019]. https://bit.ly/3inGXwP

Elorriaga, A., \& Monge, S. (2018). The professionalization of youtubers: the case of Verdeliss and the brands. Revista Latina de Comunicación Social, 73, 37-54. https://doi.org/10.4185/ RLCS-2018-1244

Flores-Vivar, J.M. (2009). New models of communication, profiles and trends in social networks. Comunicar, 17(33), 73-81. https://doi.org/10.3916/c33-2009-02-007

Frost, R, L., \& Postman, N. (1993). Technopoly: The surrender of culture to technology. Technology and Culture, 34(3), 714. https://doi.org/10.2307/3106743

Gee, P. (2005). Semiotic social spaces and affinity spaces: from the Age of Mythology to today's schools. Beyond Communities of Practice, 214-232. https://doi.org/10.1017/ cbo9780511610554.012

Gould, S. J. (1991). Exaptation: A crucial tool for an evolutionary psychology. Journal of Social Issues, 47(3), 43-65. https://doi. org/10.1111/j.1540-4560.1991.tb01822.x

Gulamhussein, A. (2013). Effective professional development in an era of high stakes accountability. Teaching the Teachers. Center for Public Education, Santa Monica, CA, United States. https:// bit.ly/3ga3MT0

Gutiérrez-Cortés, F., Islas-Carmona, O., \& Arribas-Urrutia, A. (2019). The New Laws of New Media and the Re-shaping of the Environment. Palabra Clave, 22(2), 1-27. https://doi. org/10.5294/pacla.2019.22.2.9

Jenkins, H. (2009). Confronting the challenges of participatory culture: Media education for the 21st century. Mit Press. https://doi.org/10.7551/mitpress/8435.001.0001

Jenkins, H., \& Ito, M. (2015). Participatory culture in a networked era: A conversation on youth, learning, commerce, and politics. John Wiley \& Sons. https://bit.ly/2BpyOaT

Jordán-Correa, D. J., Arias-Valladolid, C. A., \& Samaniego-Rivas, G. S. (2017). La participación del Prosumidor en la nueva era de la comunicación. INNOVA Research Journal, 2(11), 179-185. https://doi.org/10.33890/innova.v2.n11.2017.556

Kádeková, Z., \& Holienčinová, M. (2018). Influencer marketing as a modern phenomenon creating a new frontier of virtual opportunities. Communication Today, 9(2), 90-105. https://bit. ly/2NfmPSe

Lantz-Andersson, A., Lundin, M., \& Selwyn, N. (2018). Twenty years of online teacher communities: A systematic review of formally-organized \& informally-developed professional learning groups. Teaching E Teacher Education, 75, 302-315. https://doi.org/10.1016/j.tate.2018.07.008

Latorre-Iglesias, L. E., Castro-Molina, K. P., \& Potes-Comas, I. (2018). Las TIC, las TAC y las TEP: Innovación Educativa en la Era Conceptual. Universidad Sergio Arboleda. https://bit. ly/3gfBtm7

Lévy, P., \& Bononno, R. (1997). Collective intelligence: Mankind's emerging world in cyberspace. Perseus books. https://bit. ly/2YOdZPa

López Noguero, F. (2002). El análisis de contenido como método de investigación. XXI: Revista de Educacion. 4, 167-179. https:// bit.ly/2Dbwjcx

Madrigal, Á. (2015). Internet y redes sociales: ¿Caminamos hacia una nueva comunicación? Mundos emergentes: cambios, conflictos y expectativas, 61-71. https://bit.ly/3giMUJU

Montero, Ó. (2014, 23 abril). TIC TAC TEP. Tecnologías... para la vida. Conasa. https://bit.ly/2Z76wuR

Moravec, J. W. (2013). Knowmad society: The "new" work and education. On the Horizon, 21(2), 79-83. https://doi. org/10.1108/10748121311322978
Morillo, J. (2011). Introducción a los dispositivos móviles. Tecnología y Desarrollo en Dispositivos Móviles, Universitat Oberta de Catalunya. https://bit.ly/2YUWDQR

Nunnally, J. C. (1994). Psychometric theory. McGraw-Hill Education. https://bit.ly/381MdwH

Ordóñez, J. (2003). Ciencia, tecnología e historia. Fondo de Cultura Económica. https://doi.org/10.6035/estudisfilologics. 2010.30

O'Reilly, T. (2005). What is web 2.0? Design patterns and business models for the next generation of software. Oreilly. https://bit. $l y / 2 D 38 B z h$

Orta, M., \& Chávez, R. (2010). Hacia una nueva comunicación digital y participativa: Blogosfera y redes sociales en los periódicos online. Comunicación y desarrollo en la era digital [Conference]. Asociación Española de Investigación de la Comunicación, Málaga, España. https://bit.ly/31DAyaT

Pereira, S., Fillol, J., \& Moura, P. (2019). Young people learning from digital media outside of school: The informal meets the formal. Comunicar, 27(58), 41-50. https:/doi.org/10.3916/ c58-2019-04

Pérez, C. \& Moliní, A. (2004). Consideraciones generales sobre la alfabetización científica en los museos de ciencia como espacios educativos no formales. Revista Electrónica de Enseñanza de las Ciencias, 3(3), 1-26. https://bit.ly/3dULDqJ

Perez-Escoda, A. \& Garcia-Ruiz, R. (2019). Instagrammers y youtubers: Uso pedagógico para el desarrollo de la competencia digital. Competencia Mediática y Digital del Acceso al Empoderamiento, 243- 252. https://bit.ly/3gk7BFk

Piscitelli, A., Adaime, I., \& Binder, I. (2010). El proyecto Facebook y la posuniversidad. Sistemas operativos sociales y entornos abiertos de aprendizaje. Ariel. https://bit.ly/38lkcVL

Quero, M. (2010). Confiabilidad y coeficiente Alpha de Cronbach. Telos, 2(12). 248-252. https://bit.ly/3djCyaW

Rego-Rey, S., \& Romero-Rodríguez, L.M. (2016). Discursive representation and language of Spanish youtubers: Case Study of the more popular gamers. index.Comunicación, 6(1), 197-224. https://bit.ly/2eZGnHJ

Robles-Garrote, P, \& Rojas, M. (2015). La validación por juicio de expertos: dos investigaciones cualitativas en Lingüística aplicada. Revista Nebrija de lingüística aplicada a la enseñanza de lenguas, (18), 124-139. https://bit.ly/38Ah2O3

Romani, C. C., \& Kuklinski, H. P. (2007). Planeta Web 2.0: Inteligencia colectiva o medios fast food. Grup de Recerca d'Interaccions Digitals. https://bit.ly/31FzvY6

Santamaría-de la Piedra, E., \& Meana, R. (2018). Social media and «influencers». Reflections from a psychological perspective. Miscelánea Comillas, 75(147), 443-469. http://bit.ly/2Zi0EMr

Schugurensky, D. (2000). The forms of informal learning. Towards a conceptualization of the field. New Approaches for Lifelong Learning (NALL) [Conference]. Centre for the Study of Education and Work, Toronto, Canada. https://bit.ly/31AebDq

Shelton, C., \& Archambault, L. (2019). Discovering how teachers build virtual relationships and develop as professionals through online teacherpreneurship. Journal of Interactive Learning Research, 29(4), 579-602. https://bit.ly/3dO6LPf

Stegman, S. F. (2007). An exploration of reflective dialogue between student teachers in music and their cooperating teachers. Journal of Research in Music Education, 55(1), 65-82. https:// doi.org/10.1177/002242940705500106

Streiner, D. L. (2003). Starting at the beginning: an introduction to coefficient alpha and internal consistency. Journal of Personality Assessment, 80(1), 99-103. https://doi.org/10.1207/ s15327752jpa8001_18 
Tavakol, M., \& Dennick, R. (2011). Making sense of Cronbach's alpha. International Journal of Medical Education, 2, 53-55. https:// doi.org/10.5116/ijme.4dfb.8dfd

Terblanche, N. S., \& Boshoff, C. (2008). Improved scale development in marketing: An empirical illustration. International Journal of Market Research, 50(1), 105-119. https://doi. org/10.1177/147078530805000108

Trust, T., Krutka, D. G., \& Carpenter, J. P. (2016). “Together we are better": Professional learning networks for teachers. Computers $\mathcal{E}$ Education, 102, 15-34. https://doi.org/10.1016/j. compedu.2016.06.007

van-Merriënboer, J., Kirschner, P., Paas, F., Sloep, P., \& Caniëls, M. (2009). Towards an integrated approach for research on lifelong learning. Educational Technology Magazine, 49(3), 3-15. https://bit.ly/2Zsr9R6

Vescio, V., Ross, D., \& Adams, A. (2008). A review of research on the impact of professional learning communities on teaching practice and student learning. Teaching and teacher education, 24(1), 80-91. https://doi.org/10.1016/j.tate.2007.01.004

Vizcaíno-Verdú, A., Aguaded, I. \& De-Casas-Moreno, P. (2019). Youtubers e instagrammers: Una revisión sistemática cuantitativa. Competencia Mediática y Digital del Acceso al Empoderamiento, 211- 219. https://bit.ly/2D3Uz0j

Wenger, E. (1998) Communities of Practice: Learning, Meaning, and Identity. Cambridge University Press. https://doi. org/10.1017/cbo9780511803932 
